\title{
PERFIL DO CONSUMIDOR E OSCILAÇÕES DE PREÇOS DE PRODUTOS AGROECOLÓGICOS ${ }^{1}$
}

\author{
Silmara de Carvalho Barbosa ${ }^{2}$, Magda Beatriz de Almeida Matteucci², Wilson Mozena Leandro ${ }^{2}$, \\ Anderson Fernandes Leite ${ }^{2}$, Érika Lidia Silva Cavalcante ${ }^{2}$, Gustavo Queiroz Evangelista de Almeida ${ }^{2}$
}

\begin{abstract}
CONSUMER PROFILE AND PRICE

VARIATION OF AGRO-ECOLOGICAL PRODUCTS

The consumption of natural foods has increased significantly all over the world, and the term "organic" has acquired great importance. Thus, this study tried to identify the consumer profile of organic foods in Goiânia, Goiás State, Brazil, in order to find out the main difficulties faced to purchase this kind of product. Prices for organic and conventional foods were also compared. The main problem mentioned by the people questioned about the difficulties for consuming this kind of product was the price factor, followed by its availability. Pumpkin (Curcubita moschata), eggplant (Solanum melongena), beetroot (Beta vulgaris L.), carrot (Daucus carota L.), jiló (Solanum gilo Raddi), and cucumber (Cucumis sativu) were the products that showed the highest percent variation in price (conventional $\mathrm{x}$ organic).
\end{abstract}

KEY-WORDS: Organic food; consumer market; vegetables.

\section{INTRODUÇÃO}

Profundas modificações ocorreram no setor agroalimentar, nos últimos anos, e muitas destas mudanças devem-se à crescente preocupação, por parte dos consumidores, com a segurança alimentar e o meio ambiente.

Por meio da conhecida Revolução Verde, o Brasil importou tecnologias de zonas temperadas, sem a devida adequação de utilização para as condições ambientais próprias de uma região tropical. Assim, diversos problemas ambientais foram disseminados, tais como a erosão do solo, desertificação, poluição por agrotóxicos e perda de biodiversidade (Redclift \& Goodman 1991), que, por sua vez, culminaram na crise agroecológica existente atualmente. A modernização das práticas agrícolas acarretou, também,

\section{RESUMO}

Em todo o mundo, o consumo de alimentos naturais tem aumentado significativamente, e o termo "orgânico" tem se destacado. Em face disto, buscou-se conhecer o perfil do consumidor de alimentos orgânicos, no município de Goiânia (GO), bem como saber quais são as principais dificuldades por ele encontradas, na aquisição destes produtos. Fez-se, também, um levantamento de preços, a fim de serem comparados alimentos orgânicos e convencionais. O principal problema apontado pelos entrevistados, quanto à dificuldade no consumo, foi o fator preço, seguido pela disponibilidade de produtos. Abóbora (Curcubita moschata), berinjela (Solanum melongena), beterraba (Beta vulgaris L.), cenoura (Daucus carota L.), jiló (Solanum gilo Raddi) e pepino (Cucumis sativus) foram os produtos que mais apresentaram variação percentual no preço (convencional $\mathrm{x}$ orgânico).

PALAVRAS-CHAVE: Alimentos orgânicos; mercado consumidor; hortaliças.

problemas de cunho social e econômico: o problema da fome no mundo não foi solucionado e muitos produtores foram obrigados a deixar suas atividades.

$\mathrm{O}$ uso indiscriminado de agrotóxicos, fertilizantes e sementes modificadas, que possuem alta resistência a diferentes tipos de pragas e doenças, tem levado pessoas no mundo inteiro a optarem por alimentos livres de agentes químicos sintéticos, que são capazes de alterar desde o desenvolvimento sexual humano até a formação do comportamento da inteligência e o funcionamento do sistema imunológico (Colborn et al. 1997).

Diante desta realidade, o consumo de alimentos naturais tem aumentado significativamente, em todo o mundo, e o termo "orgânico" tem se destacado, por ser sinônimo de preocupação com a saúde, o corpo e a ecologia (Monteiro et al. 2004).

1. Trabalho recebido em set./2010 e aceito para publicação em out./2011 (nº registro: PAT 11854/ DOI: 10.5216/pat.v41i4.11854).

2. Universidade Federal de Goiás, Escola de Agronomia e Engenharia de Alimentos, Goiânia, GO, Brasil.

E-mails: silmara_gyn@hotmail.com,magdabeatriz@gmail.com, wilson-ufg@bol.com.br, adrs.eng@gmail.com, erika.gyn@hotmail.com, gustbsb@gmail.com. 
Analistas são cautelosos e avaliam que, a longo prazo, a indústria orgânica brasileira terá um crescimento anual otimista, predizendo o crescimento dos mercados orgânicos em torno de $20 \%$, a médio prazo. O crescimento da agricultura orgânica, entretanto, será conduzido conforme as forças de mercado (FAO 2002).

No Brasil, é notória a expansão, tanto do mercado interno quanto do externo, para produtos orgânicos. Darolt (2003) ressalta que o volume de produtos comercializados, que era de cerca de $10 \%$ ao ano, no início da década de 1990, passou a ser de $40-50 \%$, na virada do milênio.

Buainain \& Batalha (2007) classificaram os consumidores de produtos orgânicos em dois grupos. O primeiro é formado por consumidores mais antigos, que são motivados, bem informados e exigentes, quanto à qualidade biológica do produto. Estes, conforme os autores, são frequentadores de feiras verdes de produtos orgânicos. O segundo grupo é ainda pouco estudado, por ser mais recente, mas é constituído por consumidores das grandes redes de supermercados.

Matteucci \& Verano (2005) afirmam que o custo de produção da hortaliça orgânica é o mesmo da convencional, mas o volume produzido é suficiente apenas para um reduzido número de pessoas. Desta forma, o que ocorre é uma supervalorização do produto pelos supermercados, e o mercado consumidor fica restrito a pessoas de alta renda.

Este estudo objetivou realizar levantamentos, em Goiânia (GO), por meio de questionários, tanto em grandes supermercados quanto em feiras livres, a fim de se avaliar a oferta de produtos orgânicos à população goianiense e conhecer o perfil deste consumidor.

\section{MATERIAL E MÉTODOS}

Para a análise do perfil do consumidor de produtos agroecológicos, no município de Goiânia (GO), foi realizada uma pesquisa de campo. Para tanto, um questionário estruturado, composto por dez questões, foi aplicado a trezentas e nove pessoas, dentre clientes de grandes supermercados ou frequentadores de feiras livres e estabelecimentos especializados em produtos orgânicos, ao longo dos meses de agosto de 2009 a maio de 2010.

Os dados primários foram analisados por meio de estatística descritiva, análise tabular e de frequên- cia das variáveis, e as informações provenientes dos questionários foram tabuladas e processadas com o auxílio do software estatístico SAS (SAS Institute 2006).

Durante os meses de janeiro, fevereiro, março, abril, maio e junho de 2010, também foram feitos levantamentos acerca dos produtos orgânicos disponíveis para comercialização e seus respectivos preços, bem como dos preços dos produtos obtidos no cultivo convencional. Os valores obtidos foram comparados, a fim de se verificar quais produtos tiveram a maior variação percentual no preço (orgânico $\mathrm{x}$ convencional), ao longo dos meses em que foi feita a coleta dos dados.

Tal procedimento visou a caracterizar o consumidor de frutas e hortaliças orgânicas do município de Goiânia e verificar a oscilação de preços, em diversos pontos da Capital, ao longo de seis meses.

\section{RESULTADOS E DISCUSSÃO}

No universo das 309 pessoas abordadas, $58,3 \%$ eram do sexo feminino e $41,7 \%$ do sexo masculino, com idades entre 31 e 50 anos (39,81\%), sendo 48,2\% delas casadas. Quanto ao grau de escolaridade, $29,8 \%$ alegaram ter concluído o ensino médio e $36,9 \%$ afirmaram possuir curso superior completo.

Dentre as pessoas questionadas, $31 \%$ disseram não consumir alimentos orgânicos, enquanto as demais afirmaram consumi-los com frequências variadas (Figura 1a). Zamberlan et al. (2006) constataram que $14,58 \%$ dos consumidores tinham o hábito de consumir este tipo de alimento diariamente. Em Goiânia, este percentual foi superior (27\%). Tais resultados levam a crer que as pessoas que consomem alimentos orgânicos tendem a incorporá-los, com relativa frequência, à sua dieta.

Quando questionadas se sabiam o que são alimentos orgânicos, 92,6\% alegaram que sabiam e apenas $7,4 \%$ disseram que não, o que indica que o termo "orgânico" já está bastante difundido. Entretanto, na avaliação, não se conheceu o nível de informações que os entrevistados tinham acerca do tema.

Em pesquisa desenvolvida por Monteiro et al. (2004), no Estado de São Paulo, concluiu-se que o conceito de orgânicos está disseminado na população: na análise dos resultados, não houve diferença significativa nas respostas por sexo, estado civil e renda, quanto à definição de alimentos orgânicos. Todavia, verificou-se que $60 \%$ dos entrevistados concordavam 
com a definição tecnicamente equivocada de que alimentos orgânicos são somente aqueles produtos livres de agrotóxicos.

Foi observado que o fator que mais motiva o consumidor de alimentos orgânicos a optar pelo produto é a ideia de que estes sejam mais saudáveis, quando comparados ao convencional (61\%). Os principais fatores motivadores de consumo estão relacionados ao fato de o alimento orgânico ser mais saudável, conservar mais a natureza e não utilizar veneno/agrotóxico, além de haver, também, motivações decorrentes da combinação destes fatores (Figura 1b).

A constatação de que $61 \%$ das pessoas entrevistadas consomem produtos orgânicos por serem estes mais saudáveis conduz a uma percepção de que há, para o consumidor, uma forte conexão entre alimentos orgânicos e saúde. Monteiro et al. (2004) observaram que a crença de que os orgânicos são benéficos à saúde cresce à medida que aumenta a frequência de compra e de consumo. Os autores perceberam, também, que, quando a pessoa que compra é a própria consumidora final do produto, a opinião acerca da relação entre saúde e alimentos orgânicos é mais favorável do que quando outra pessoa realiza a compra.

O segundo fator mais mencionado, no quesito motivo de consumo, foi o fato de o alimento não conter veneno/agrotóxico (21\%). Este fator, possivelmente, reflete a preocupação dos consumidores com os resíduos químicos que podem permanecer no organismo, o que pode sinalizar preocupação com a saúde.

Analisando-se as características de percepção de valor, para os produtos com ausência de insumos químicos, Pimenta \& Vilas Boas (2010) salientaram que o atributo "ausência de produtos químicos" provoca, no consumidor, a sensação de menor necessidade de cuidados sanitários com os alimentos (em relação aos convencionais), resultando em maior praticidade e ganho de tempo. A preocupação

(a)

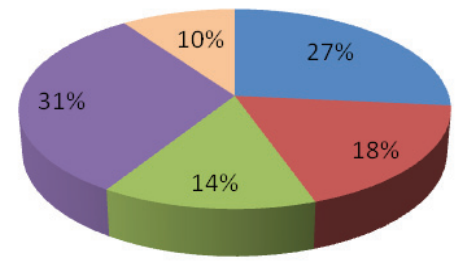

em consumir produtos sem insumos químicos visa, também, a atingir estados como felicidade, bem-estar e longevidade.

Apenas 3\% das pessoas questionadas disseram consumir alimentos orgânicos porque são menos prejudiciais à natureza. Esta baixa percentagem não indica, todavia, que as pessoas não tenham preocupação com o meio ambiente, ou que não exista uma associação clara entre proteção ao meio ambiente e produtos orgânicos. Monteiro et al. (2004) afirmam que a percepção de que alimentos orgânicos e qualidade ambiental estão relacionados tende a aumentar, à medida em que se elevam a idade, a escolaridade $\mathrm{e}$ a renda da população.

Os entrevistados responderam, também, que o consumo se dá porque o alimento é mais saudável, não utiliza veneno/agrotóxico e conserva mais a natureza (4\%), fazendo uma combinação de fatores. Este grupo talvez englobe pessoas mais esclarecidas acerca do tema.

Mesmo consumindo alimentos orgânicos, 3\% das pessoas questionadas disseram não identificar vantagens neste consumo. Este fator talvez se deva ao consumo influenciado pela família. Segundo Zamberlan et al. (2006), a família é a principal influência no comportamento de consumo de seus membros. Schiffman \& Kanuk (2000) salientam que a família, comumente, oferece a oportunidade de exposição e da experimentação do produto e é capaz de transmitir os valores de consumo aos seus membros.

A pesquisa indicou que o maior problema relacionado ao consumo é o fator preço, seguido dos itens disponibilidade e variedade de produtos (Figura 2a).

Quando questionados acerca do problema no consumo, em lojas especializadas e feiras orgânicas (Tabela 1), 33,6\% dos inqueridos disseram ser o preço o principal fator inibitório. Dentre os que consomem

(b)

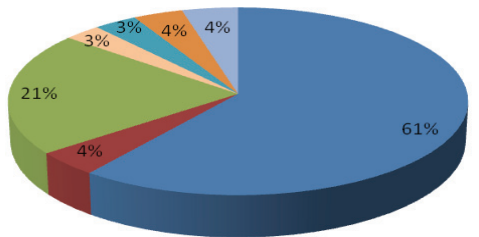

Figura 1. Frequência de consumo (a) de alimentos orgânicos e fatores motivancionais (b) para o seu consumo, em Goiânia, GO (agosto de 2009 a maio de 2010). 
Tabela 1. Perfil do consumidor de orgânicos em Goiânia (GO), em relação ao tipo de estabelecimento comercial frequentado (2009/2010).

\begin{tabular}{|c|c|c|}
\hline \multirow[t]{2}{*}{ Parâmetro } & $\begin{array}{l}\text { Estabelecimentos que comercializam exclusivamente } \\
\text { produtos orgânicos }\end{array}$ & Outros tipos de estabelecimentos \\
\hline & Feiras de produtos orgânicos e lojas especializadas & Supermercados \\
\hline Sexo & Masculino (44\%); feminino (56\%) & Masculino (40\%); feminino (60\%) \\
\hline Idade & $\begin{array}{l}\text { Até } 30 \text { anos }(14,2 \%) \text {; entre } 31 \text { e } 50 \text { anos }(45,5 \%) ; \\
\text { acima de } 51 \text { anos }(40,3 \%)\end{array}$ & $\begin{array}{c}\text { Até } 30 \text { anos }(49,1 \%) \text {; entre } 31 \text { e } 50 \text { anos }(35,4 \%) ; \\
\text { acima de } 51 \text { anos }(15,4 \%)\end{array}$ \\
\hline Escolaridade & $\begin{array}{l}\text { Ensino médio completo }(33,6 \%) \text {; curso superior } \\
\text { completo ou em fase de conclusão }(46,3 \%)\end{array}$ & $\begin{array}{l}\text { Ensino médio completo }(26,9 \%) \text {; curso superior } \\
\text { completo ou em fase de conclusão }(60,6 \%)\end{array}$ \\
\hline $\begin{array}{l}\text { Frequência de } \\
\text { consumo }\end{array}$ & $\begin{array}{c}\text { Todos os dias }(47,0 \%) \text {; uma vez por semana }(20,9 \%) \\
2 \text { a } 3 \text { vezes por semana }(18,7 \%) \text {; não consomem } \\
(6,0 \%) \text {; outras frequências }(7,5 \%)\end{array}$ & $\begin{array}{l}\text { Todos os dias }(10,9 \%) \text {; uma vez por semana } \\
(16,0 \%) ; 2 \text { a } 3 \text { vezes por semana }(10,9 \%) ; \text { não } \\
\text { consomem }(50,9 \%) \text {; outras frequências }(11,4 \%)\end{array}$ \\
\hline $\begin{array}{l}\text { Conhecimento dos } \\
\text { consumidores }\end{array}$ & $\begin{array}{l}\text { Disseram saber o que são alimentos orgânicos } \\
(94,8 \%) \text {; disseram não o saber }(5,2 \%)\end{array}$ & $\begin{array}{l}\text { Disseram saber o que são alimentos orgânicos } \\
(90,9 \%) \text {; disseram não o saber }(9,1 \%)\end{array}$ \\
\hline $\begin{array}{l}\text { Motivo do } \\
\text { consumo }\end{array}$ & $\begin{array}{c}\text { É mais saudável }(69,0 \%) \text {; não utiliza veneno/ } \\
\text { agrotóxico }(8,7 \%) \text {; conserva mais a natureza }(6,3 \%) \text {; } \\
\text { é mais saudável e conserva mais a natureza }(4,8 \%) ; \\
\text { é mais saudável e não utiliza veneno/agrotóxico } \\
(3,2 \%) \text {; é mais saudável, conserva mais a natureza e } \\
\text { não utiliza veneno/agrotóxico }(5,6 \%)\end{array}$ & $\begin{array}{l}\text { É mais saudável (47,7\%); não utiliza veneno/ } \\
\text { agrotóxico (40,7\%); conserva mais a natureza } \\
\text { (1,2\%); é mais saudável e não utiliza veneno/ } \\
\text { agrotóxico (4,7\%); é mais saudável, conserva mais } \\
\text { a natureza e não utiliza veneno/agrotóxico }(2,3 \%)\end{array}$ \\
\hline $\begin{array}{l}\text { Problemas } \\
\text { encontrados no } \\
\text { consumo }\end{array}$ & $\begin{array}{c}\text { Preços }(33,6 \%) \text {; disponibilidade de produtos } \\
(27,6 \%) \text {; variedade de produtos }(17,2 \%) ; \\
\text { disponibilidade de produtos e preços }(5,2 \%) ; \\
\text { disponibilidade e variedade de produtos }(2,2 \%) ; \\
\text { disponibilidade, preços e variedade de produtos } \\
(2,2 \%) \text {; não há problemas }(11,9 \%)\end{array}$ & $\begin{array}{c}\text { Preços }(56,6 \%) \text {; disponibilidade de produtos } \\
(22,9 \%) \text {; variedade de produtos }(5,7 \%) ; \\
\text { disponibilidade de produtos e preços }(3,4 \%) ; \\
\text { disponibilidade, preços e variedade de produtos } \\
(1,7 \%) \text {; não há problemas }(9,7 \%)\end{array}$ \\
\hline $\begin{array}{l}\text { Como sabem que o } \\
\text { que vão consumir é } \\
\text { orgânico }\end{array}$ & $\begin{array}{l}\text { Origem do produto }(34,9 \%) \text {; credibilidade do vendedor } \\
(26,2 \%) \text {; etiqueta/selo }(20,6 \%) \text {; aparência do produto } \\
(16,9 \%) \text {; etiqueta/selo e origem }(0,8 \%) \text {; aparência do } \\
\text { produto e credibilidade do vendedor }(0,8 \%) \text {; etiqueta/ } \\
\text { selo e credibilidade do vendedor }(0,8 \%)\end{array}$ & $\begin{array}{c}\text { Origem do produto }(24,4 \%) \text {; credibilidade } \\
\text { do vendedor }(10,5 \%) \text {; etiqueta/selo }(48,8 \%) ; \\
\text { aparência do produto }(15,1 \%) \text {; etiqueta/selo e } \\
\text { origem }(1,2 \%)\end{array}$ \\
\hline $\begin{array}{l}\text { Renda média (em } \\
\text { salários mínimos) }\end{array}$ & $\begin{array}{c}\text { De } 0 \text { a } 2(28,4 \%) ; \text { de } 3 \text { a } 4(28,4 \%) ; \text { de } 5 \text { a } 7 \\
(17,2 \%) \text {; de } 8 \text { a } 10(9,7 \%) \text {; acima de } 10(16,4 \%)\end{array}$ & $\begin{array}{l}\text { De } 0 \text { a } 2(40,0 \%) ; \text { de } 3 \text { a } 4(28,0 \%) ; \text { de } 5 \text { a } 7 \\
(21,7 \%) \text {; de } 8 \text { a } 10(5,1 \%) ; \text { acima de } 10(5,1 \%)\end{array}$ \\
\hline
\end{tabular}

produtos orgânicos em supermercados, a percentagem para a opção preço foi de $56,6 \%$. Esta informação permite afirmar que, mesmo entre os consumidores de produtos orgânicos em lojas especializadas e feiras orgânicas, existe uma barreira no consumo, em função do preço que eles têm que pagar para adquirir o produto. Entretanto, conforme indicaram vários empresários e consultores, durante a Conferência da Organic Trade Association, em maio de 2005, a diferença entre o preço do produto orgânico e do convencional tenderá a se reduzir (Buainain \& Batalha 2007).

A disponibilidade de produtos foi apontada como fator limitante ao consumo por $27,6 \%$ dos entrevistados em feiras e lojas especializadas e $22,9 \%$ daqueles entrevistados em supermercados (Tabela 1), fato que pode ser explicado pela baixa oferta de pro- dutos, frente a uma demanda cada vez mais elevada, por parte dos consumidores.

Em Goiânia, segundo Fleury \& Lima (2005), apenas cerca de $30 \%$ dos supermercados comercializam produtos orgânicos, sendo que a comercialização é maior naqueles de grande porte. Dentre estes, $60 \%$ dispõem do produto para comercialização. O principal motivo alegado pelos responsáveis por estabelecimentos que não comercializam produtos orgânicos é que há falta de fornecedores dos produtos.

Verifica-se, ainda, que $11 \%$ das pessoas abordadas afirmaram que o problema principal no consumo é a variedade de produtos (Figura 2a). Este problema se deve ao fato de que nem todos os produtos convencionais têm seus correspondentes 
orgânicos sendo vendidos em qualquer época do ano, dadas as dificuldades de condução da cultura.

Dentre os entrevistados, $11 \%$ disseram que não enfrentam quaisquer problemas no consumo de produtos orgânicos. Para estas pessoas, os preços não interferem no consumo, as variedades disponíveis satisfazem às suas necessidades e há adequação, em relação à disponibilidade do produto.

Considerando-se as pessoas que combinaram diferentes fatores, o item disponibilidade foi constante. Os fatores apontados foram: disponibilidade e preços (4\%); disponibilidade e variedade de produtos (1\%); e disponibilidade, preços e variedade de produtos $(2 \%)$.

Quando questionados sobre como ter certeza de que o que estão consumindo é orgânico, 32\% responderam que é por meio da etiqueta/selo, $31 \%$ alegaram que o sabem por causa da origem do produto (ou seja, acreditam saber a procedência da mercadoria) e 20\% atribuíram tal crença à credibilidade do vendedor (Figura 2b). Quando a análise considerou o tipo de estabelecimento frequentado pelo consumidor (feira/lojas especializadas x supermercados), o item credibilidade do vendedor (Tabela 1) foi superior em feiras e estabelecimentos com foco em orgânicos $(26,2 \%)$, enquanto este mesmo fator totalizou $10,5 \%$, em grandes supermercados.

Ainda considerando-se os tipos de estabelecimento comercial, o fato de $20,6 \%$ das pessoas que frequentam feiras e estabelecimentos que comercializam produtos orgânicos terem respondido que sabem que estão consumindo gêneros orgânico por causa da etiqueta/selo demonstra falta de conhecimento, por parte do consumidor, porque, neste caso, ele compra diretamente do produtor e a embalagem não especifica se o produto é ou não certificado.

(a)

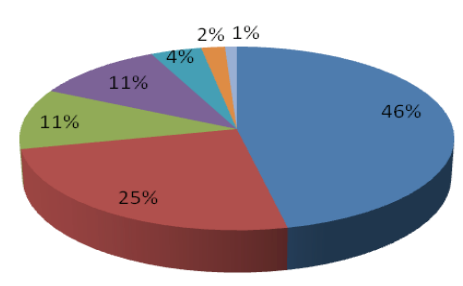

Um total de $15,1 \%$ dos frequentadores de supermercados e $16,9 \%$ daqueles que frequentam feiras e estabelecimentos especializados em produtos orgânicos sabem que os estão consumindo por sua aparência (Tabela1). Em análise feita por Pimenta \& Vilas Boas (2010), os consumidores que preferem produtos menos bonitos o fazem porque consideram que aqueles com pior aparência não contêm produtos químicos, substâncias responsáveis por conferir melhor aspecto visual ao produto. Desta forma, o consumidor com aprimoramento intelectual entende que a pior aparência é uma qualidade desejável, que pode beneficiá-lo na redução do uso de medicamentos, sendo, portanto, de qualidade superior.

Verificou-se que a confiança, em relação ao fornecedor (credibilidade), é maior em feiras orgânicas e lojas especializadas, do que em supermercados. Este fato talvez deva-se ao grau de proximidade entre o produtor e o consumidor.

Mais de $60 \%$ das pessoas entrevistadas têm renda de até 4 salários mínimos e 10\% têm renda superior a 10 salários (Figura 3). Verificou-se a existência de maior número de pessoas de alta renda, dentre as que consomem produtos orgânicos, em re-

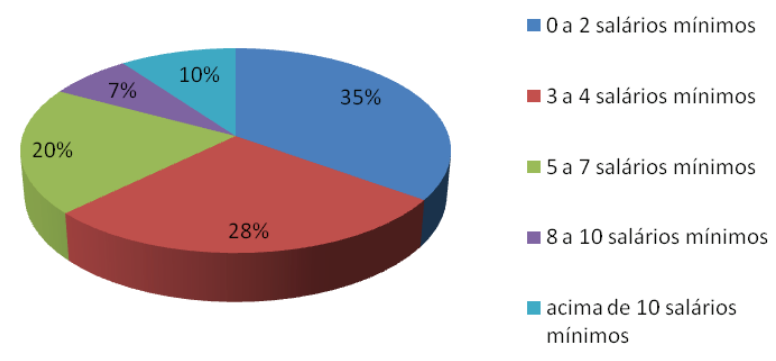

Figura 3. Renda média das pessoas entrevistadas acerca de produtos orgânicos (Goiânia, GO, 2009/2010).

(b)

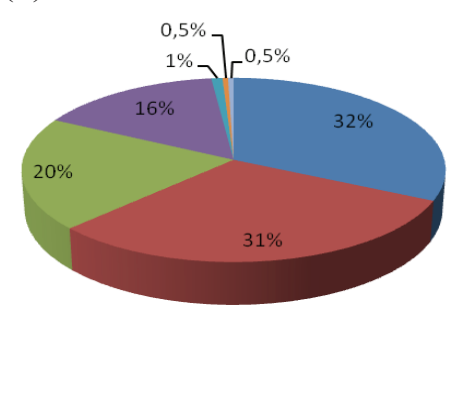

Figura 2. Principais obstáculos ao consumo (a) e percepção do consumidor (b) acerca da garantia do produto orgânico, em Goiânia, GO (agosto de 2009 a maio de 2010). 
lação ao grupo das que não os consomem (Tabela 1). Trata-se, portanto, de um grupo que tem condições de pagar um pouco mais pelo produto, embora veja o fator preço como problema para o consumo.

Pesquisas realizadas no Brasil, sobre o perfil dos consumidores de alimentos, apresentam dados semelhantes aos encontrados em países mais desenvolvidos. Portilho (2010), Cerveira \& Castro (1999), Rucinski \& Brandenburg (2002), Assis (1993) e Campos (1998) identificaram o mesmo perfil de consumidores: entre 30 e 50 anos, geralmente do sexo feminino, com instrução elevada, de classe média e com hábito de consumo diversificado. As motivações para se comprar produtos orgânicos seriam a saúde pessoal e familiar, seguidas da não-utilização de agroquímicos, valor biológico, sabor e aroma, e, por último, preocupação com o meio ambiente.

Em relação à qualidade dos produtos orgâni$\cos$, foram registradas reclamações, quanto à regularidade de oferta e o baixo número de pontos de venda. Buainain \& Batalha (2007) citam alguns pontos de estrangulamento, para os produtores venderem seus produtos orgânicos em supermercados, como se segue: baixo volume de produção; descontinuidade na quantidade e falta de padronização da qualidade ofertada; fraca infraestrutura de produção e comercialização; baixa disponibilidade de recursos produ- tivos (capital e mão-de-obra); pouca organização dos pequenos agricultores e trabalhadores rurais; baixa remuneração dos agricultores pelo produto orgânico; e promoção e publicidade escassas.

Segundo Souza \& Alcântara (2003), não existe, no mercado de produtos orgânicos, um parâmetro definido para o estabelecimento de preços, embora as estratégias de atribuição para os mesmos variem amplamente, conforme o estabelecimento comercial.

Na Tabela 2, são destacados os produtos que mais apresentaram variação percentual de preço (orgânico x convencional), ao longo dos meses em que foi feita a coleta dos dados: abobrinha brasileira (Curcubita moschata), berinjela (Solanum melongena), beterraba (Beta vulgaris L.), cenoura (Daucus carota L.), jiló (Solanum gilo Raddi) e pepino (Cucumis sativus). Em janeiro de 2010, não foram encontrados beterraba e pepino orgânicos.

A banana maçã (Musa spp.) orgânica teve um sobrepreço médio de $25 \%$, em relação ao produto convencional. O kiwi (Actinidia deliciosa), encontrado nos meses de março e junho, apresentou sobrepreço de $98,46 \%$ e $317,02 \%$, respectivamente.

Quanto a hortaliças, a diferença percentual dos preços está listada na Tabela 3. O consumidor encontra dificuldades para comparar os preços destas hortaliças em grandes supermercados, uma vez que a

Tabela 2. Variação percentual dos preços de produtos orgânicos e convencionais, ao longo de janeiro a junho de 2010, em Goiânia (GO).

\begin{tabular}{ccccccc}
\hline Produto & Janeiro & Fevereiro & Março & Abril & Maio & Junho \\
\hline Abobrinha brasileira & 100,00 & 160,92 & 236,78 & 115,01 & 262,74 & 239,07 \\
Berinjela & 198,80 & 306,64 & 238,35 & 179,86 & 107,95 & 102,92 \\
Beterraba & - & 159,20 & 215,73 & 187,95 & 211,83 & 320,20 \\
Cenoura & 42,35 & 125,87 & 161,95 & 192,60 & 628,06 & 257,56 \\
Jiló & 111,22 & 264,71 & 133,26 & 134,62 & 78,31 & 129,60 \\
Pepino & - & 224,40 & 219,74 & 175,24 & 295,51 & 297,15 \\
\hline
\end{tabular}

Tabela 3. Variação percentual dos preços de hortaliças orgânicas e convencionais, ao longo de janeiro a junho de 2010, em Goiânia (GO).

\begin{tabular}{ccccccrr}
\hline Produto & $\begin{array}{c}\text { Forma de } \\
\text { comercialização }\end{array}$ & Janeiro & Fevereiro & Março & Abril & Maio & Junho \\
\hline Acelga & unidade & - & 19,33 & 14,34 & - & - & 109,57 \\
Alface americana & unidade & 117,39 & $-17,47$ & $-20,44$ & $-36,51$ & 60,32 & 7,13 \\
Brócolis & unidade & - & 108,26 & $-34,07$ & - & 43,54 & $-26,69$ \\
Cebolinha & maço/unidade & - & 82,57 & $-15,87$ & - & - & 43,35 \\
Chicória & unidade & - & 38,33 & 20,00 & - & 0,50 & 17,13 \\
Couve & maço/unidade & - & 86,33 & 17,75 & - & 43,92 & 18,29 \\
Espinafre & unidade & - & 82,57 & $-3,24$ & 22,86 & 52,09 & 30,32 \\
Hortelã & maço/unidade & - & 82,57 & 5,29 & 34,80 & 19,50 & 28,44 \\
Rúcula & unidade & - & 26,00 & 2,58 & 21,36 & 35,96 & 43,72 \\
\hline
\end{tabular}


forma de apresentação não é padronizada. A título de exemplificação: em alguns supermercados, a salsa e a rúcula são vendidas por maço ou unidade, enquanto, em outros estabelecimentos, a comercialização é feita por quilo. Esta dificuldade também é encontrada em um mesmo estabelecimento, para produtos convencionais e orgânicos: em um dos supermercados avaliados, a rúcula orgânica foi comercializada por $\mathrm{R} \$ 12,20 / \mathrm{kg}$, enquanto a rúcula convencional foi vendida por $\mathrm{R} \$ 1,99 /$ unidade.

Estudos indicam que a tendência é que a diferença percentual entre produtos orgânicos e convencionais decresça, embora a mesma dependa das taxas de crescimento da demanda e da oferta de produtos orgânicos (Buainain \& Batalha 2007).

A venda em feiras de produtos orgânicos e estabelecimentos especializados é feita em embalagens previamente preparadas e, geralmente, se dá por volume (aproximadamente $600 \mathrm{~g}$ do produto por embalagem). Em supermercados, os produtos orgânicos também são vendidos embalados (normalmente em bandejas ou saquinhos, dependendo do vegetal), com a diferença de que, nestes, existe informação sobre o peso do produto ofertado.

Em alguns supermercados, os produtos orgânicos ofertados são dispostos quase conjuntamente aos produtos convencionais e a maneira de informar ao consumidor os preços da mercadoria não se dá de maneira eficaz, gerando confusão e desconfiança, por parte de quem adquire o produto.

Estando o mercado de orgânicos, no Brasil, em franca expansão, o conhecimento acerca do comportamento dos consumidores de produtos orgânicos é fundamental para orientar trabalhos de produção e direcionar os esforços de marketing sobre orgânicos. Por isto, sugerem-se novas investigações, especialmente quando se considera que o País deve ficar entre os maiores produtores mundiais, nos próximos anos (Buainain \& Batalha 2007).

\section{CONCLUSÕES}

1. O principal problema apontado pelos entrevistados, quanto à dificuldade no consumo de produtos orgânicos, é o fator preço, seguido pela disponibilidade de produtos.

2. Abobrinha brasileira (Curcubita moschata), berinjela (Solanum melongena), beterraba (Beta vulgaris L.), cenoura (Daucus carota L.), jiló (Solanum gilo Raddi) e pepino (Cucumis sativus) foram os produtos que mais apresentaram variação percentual no preço (convencional x orgânico).

3. Verificou-se a existência de maior número de pessoas de alta renda, dentre as que consomem produtos orgânicos, em relação ao grupo das que não os consomem.

\section{REFERÊNCIAS}

ASSIS, R. L. de. Diagnóstico da agricultura orgânica no Estado do Rio de Janeiro e propostas para a sua difusão. 1993. 154 f. Dissertação (Mestrado em Ciências do Solo)-Universidade Federal Rural do Rio de Janeiro, Rio de Janeiro, 1993.

BUAINAIN, A. M.; BATALHA, M. O. Agronegócios: cadeia produtiva de produtos orgânicos. Brasília, DF: IICA/MAPA/SPA, 2007.

CAMPOS, F. F. de. O mercado de produtos orgânicos: o caso do Rio de Janeiro. 1998. 65 f. Trabalho de Conclusão de Curso (Graduação em Geografia)-Pontifícia Universidade Católica, Rio de Janeiro, 1998.

CERVEIRA, R.; CASTRO, M. C. de. Perfil socioeconômico dos consumidores de produtos orgânicos da cidade de São Paulo. 1999. Disponível em: <http://www.megaagro.com. br/organica/perfil_um.asp>. Acesso em: dez. 2011.

COLBORN, T.; DUMANOSKI, D.; MYERS, J. P. O futuro roubado. São Paulo: L\&PM, 1997.

DAROLT, M. Cenário internacional: situação da agricultura orgânica em 2003. 2003. Disponível em: $<$ http://www.iapar.br/arquivos/File/zip_pdf/Darolt $\% 20$ -\%20Atualiza\%20 Agric [1].Org.\%20Mundo\%202003. pdf>. Acesso em: 15 jun. 2010.

FLEURY, F. A. B. R.; LIMA, W. M. de. Mercado orgânico: potencial em expansão. 2005. Disponível em: $<$ http:// www.seplan.go.gov.br/sepin/ pub/conj/conj7/04.htm>. Acesso em: 15 jun. 2010.

FOOD AND AGRICULTURE ORGANIZATION OF THE UNITED NATIONS (FAO). Environment and Natural Resources Service Sustainable Development Department. Organic agriculture, environment and food security. FAO: Roma, 2002.

MATTEUCCI, M. B. de A.; VERANO, T. de C. Comercialização e mercado para hortaliças orgânicas. In: ENCONTRO INTERNACIONAL DEAGROECOLOGIA E DESENVOLVIMENTO RURAL, 2., 2005, Botucatu. Resumos... Botucatu: Instituto Giramundo Mutuando, 2005. p. 1-3.

MONTEIRO, M. N. de C. et al. Os alimentos orgânicos e a percepção de seus atributos por parte dos consumidores. 
In: SEMINÁRIOS EM ADMINISTRAÇÃO FEA-USP, 7., 2004, São Paulo. Anais eletrônicos... São Paulo: USP, 2004. Disponível em: <http://www.ead.fea.usp. $\mathrm{br} /$ Semead $/ 7 \mathrm{semead} /$ paginas/artigos\%20recebidos/ marketing/MKT08>. Acesso em: 13 jun. 2010.

PORTILHO, F. Autoatribuição de responsabilidade: consumo de alimentos orgânicos em uma feira certificada. Etnográfica, Lisboa, v. 14, n. 3, p. 549-565, 2010.

PIMENTA, M. L.; VILAS BOAS, L. H. de B. Percepções de consumidores de alimentos orgânicos na cidade de Uberlândia na perspectiva de valores: uma aplicação da laddering e cadeia de meios e fins. 2010. Disponível em: $<$ http://www.planetaorganico.com.br/trabMarcioPimenta. htm>. Acesso em: 13 jun. 2010.

REDCLIFT, M.; GOODMAN, D. The machinery of hunger: the crisis of Latin America food systems. In: GOODMAN, D.; REDCLIFT, M. Environment and development in Latin America. Manchester: Manchester University Press, 1991. p. 48-78.

RUCINSKI, J.; BRANDENBURG, A. Consumidores de alimentos orgânicos em Curitiba. In: ENCONTRO DA ANPPAS, 1., 2002, Indaiatuba. Anais... Indaiatuba: ANPPAS, 2002. Disponível em: <http://www.anppas. org.br/encontro_anual/encontro1/gt/agricultura_meio_ ambiente/Jeane\%20Rucinski.pdf $>$. Acesso em: dez. 2011.
SAS INSTITUTE. SAS/STAT user's guide: version 6. 4. ed. Cary: SAS Institute, 2006.

SCHIFFMAN, L. G.; KANUK, L. L. Comportamento do consumidor. Rio de Janeiro: LTC, 2000.

SOUZA, A. P. O; ALCÂNTARA, R. L. C. Alimentos orgânicos: estratégias para o desenvolvimento do mercado. In: NEVES, M. F; CASTRO, L. T. (Orgs.). Marketing e estratégia em agronegócios e alimentos. São Paulo: Atlas, 2003. p. 332-347.

ZAMBERLAN, L.; BÜTTENBENDER, P. L.; SPAREMBERGER, A. O comportamento do consumidor de produtos orgânicos e seus impactos nas estratégias de marketing. In: ENCONTRO ANUAL DA ANPAD, 30., 2006, Salvador. Anais eletrônicos... Salvador: ANPAD, 2006. Disponível em: <http://www.anpad.org.br/ enanpad/2006/dwn/enanpad2006-gctd-2027.pdf>. Acesso em: 15 jun. 2010. 